Musées, Patrimoine et Culture scientifiques et techniques

$112 \mid 2007$

juillet - août 2007

\title{
Muséologie participative et Éducation
}

\section{María Isabel Orellana Rivera}

URL : http://journals.openedition.org/ocim/730

DOI : $10.4000 /$ ocim. 730

ISSN : 2108-646X

Éditeur

OCIM

Édition imprimée

Date de publication : 1 juillet 2007

Pagination : 12-21

ISSN : 0994-1908

\section{Référence électronique}

María Isabel Orellana Rivera, « Muséologie participative et Éducation », La Lettre de l'OC/M [En ligne],

112 | 2007, mis en ligne le 15 février 2011, consulté le 10 décembre 2020. URL : http://

journals.openedition.org/ocim/730; DOI : https://doi.org/10.4000/ocim.730 


\section{Muséologie participative et Éducation}

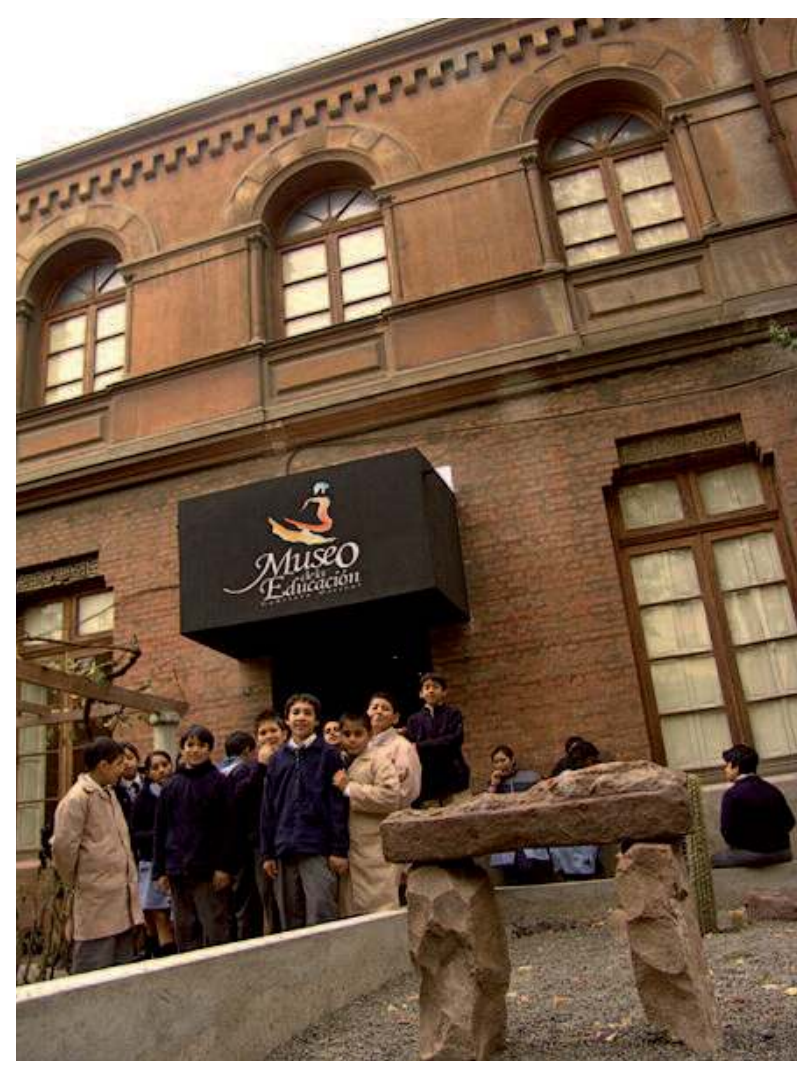

L'entrée du musée de l’Éducation Gabriela Mistral (c) MEGM/Christian Moreno

* María Isabel Orellana Rivera est directrice du musée de l'Éducation Gabriela Mistral à Santiago du Chili

Chacabuco 365 8350490 Santiago du Chili téléphone + 5626818169 contacto@museopedagogico.cl

\author{
María Isabel Orellana Rivera *
}

Ouvert en mars 2006, le musée de I'Éducation Gabriela Mistral à Santiago du Chili a bénéficié d'un programme de rénovation basé sur le concept de muséologie participative : la responsable de l'institution présente le contexte de cette rénovation et les principales étapes d'une démarche pertinente de promotion des cultures locales et d'association de la population à un projet.

Le musée de l'Éducation Gabriela Mistral est une institution qui vient de connaître un profond processus de rénovation tant du point de vue de sa conception muséologique que du bâtiment qui l'abrite. Dépositaire du patrimoine chilien de l'éducation, il est l'écho des attentes d'une communauté locale. Il constitue une réponse aux besoins d'une population urbaine qui, au-delà des loisirs, aspire à trouver dans ses institutions des symboles de la ville qui reflètent et renforcent son sentiment d'appartenance à une communauté (Orellana, 2006).

\section{Contexte d'évolution des musées des sciences en Amérique du Sud}

L'Histoire de l'éducation dans les pays latino-américains a toujours été étroitement liée à celle de la culture (Cruz, 2002), association particulièrement évidente au Chili au cours du XIX ${ }^{\mathrm{e}}$ siècle. On note également à cette époque un certain sentiment d'urgence lié à la fragilité et à la vulnérabilité de ces expériences politiques qu'étaient les Républiques 
récemment formées. Ainsi, l'histoire de l'Amérique Latine indépendante est une histoire tourmentée, au cours de laquelle les élites créoles qui conquirent leurs indépendances ont mis en place des systèmes pour contrôler les processus électoraux et pour assurer leurs pouvoirs et leurs privilèges. De ce fait, tout au long des $\mathrm{XIX}^{\mathrm{e}}$ et $\mathrm{XX}^{\mathrm{e}}$ siècles, se produisent dans presque tous les pays de la région, des révolutions, des coups d'état militaires, des interventions étrangères... Ces péripéties politiques vont entraîner une très grande instabilité socio-politique et l'installation à partir des années 1960 de dictatures militaires dans presque tous les pays de l'Amérique du Sud. Pendant cette période le système éducatif a progressivement souffert d'une diminution de la qualité de l'enseignement en général et de l'enseignement des sciences en particulier.

De nos jours, la démocratie est un système politique qui se consolide en Amérique Latine. Cependant, le processus de transition à la démocratie (1) génère aussi de profonds changements sociaux et comportementaux ${ }^{(2)}$. Dans ce contexte, surgissent de nouveaux thèmes de réflexion qui reflètent les aspirations de la société. L'éducation apparaît donc comme l'élément clé de toute tentative de démocratisation, attendu qu'elle permet aux citoyens l'acquisition des connaissances, mais aussi des compétences et des modes de relations indispensables pour participer aux nouvelles pratiques démocratiques (3). Dans ce contexte, le musée, en tant que partie intégrante des opérateurs culturels doit se préparer pour satisfaire les nécessités et les attentes du monde scolaire, mais aussi pour diversifier son offre vis-àvis d'autres publics potentiels (Orellana, 2005). C'est pour cette raison que nous avons étudié la naissance et l'évolution des musées scientifiques, notamment des centres de culture scientifique, technique et industrielle (CCSTI), en Amérique Latine et au Chili, afin de savoir comment ces institutions se sont placées par rapport à l'enseignement des sciences et à l'utilisation de l'espace muséal dans un scénario post dictatures.

Dans ce cadre, et en essayant d'établir un parallèle entre les politiques culturelles menées en Amérique Latine et en Europe occidentale, nous avons pu déceler une particularité qui concerne la création des musées scientifiques. Lorsqu'en Europe la création de ces institutions part très souvent d'une initiative de l'État, en Amérique Latine de nombreuses initiatives relèvent soit du domaine privé (parrainages, fondations, associations...) soit d'institutions qui appuient la tâche de l'État en matière culturelle (universités, centres de recherche...). Ainsi, plusieurs institutions universitaires ou centres de recherche ont pris en charge la création de divers CCSTI dans le but de participer activement à l'amélioration d'un enseignement des sciences jugé le plus souvent obsolète. De la sorte, ils ont assumé une mission habituellement dévolue à l'État, celle d'assurer l'éducation ou le libre accès à la culture scientifique pour tous les citoyens. Ce processus a contribué, d'une part, à une meilleure diffusion du savoir scientifique et, d'autre part, à une redéfinition du rôle des musées dans l'enseignement des sciences mais il a aussi lentement conduit à une scolarisation de l'espace muséal (Orellana, De la Jara, 1999).

\section{La place actuelle accordée aux musées dans I'enseignement des sciences au Chili}

Une étude menée auprès des enseignants en poste ayant visité le musée des Sciences et de la Technologie de Santiago pendant les années 1998/2002, nous a permis de constater que ceux-ci voient dans l'institution muséale un fournisseur potentiel de matériels de laboratoires leur permettant de combler les déficiences de l'école en matière scientifique. Ainsi, le musée devient une institution visant à palier les déficiences du système éducatif. Selon la nomenclature établie par Fortin-Débart (2004), cette approche de l'institution muséale correspond bien plus à un partenariat de type instrumental qu'à celui d'un partenariat de recherche-action collaborative qui susciterait « une dynamique d'autoformation permanente et autonome ». Cette représentation utilitaire est

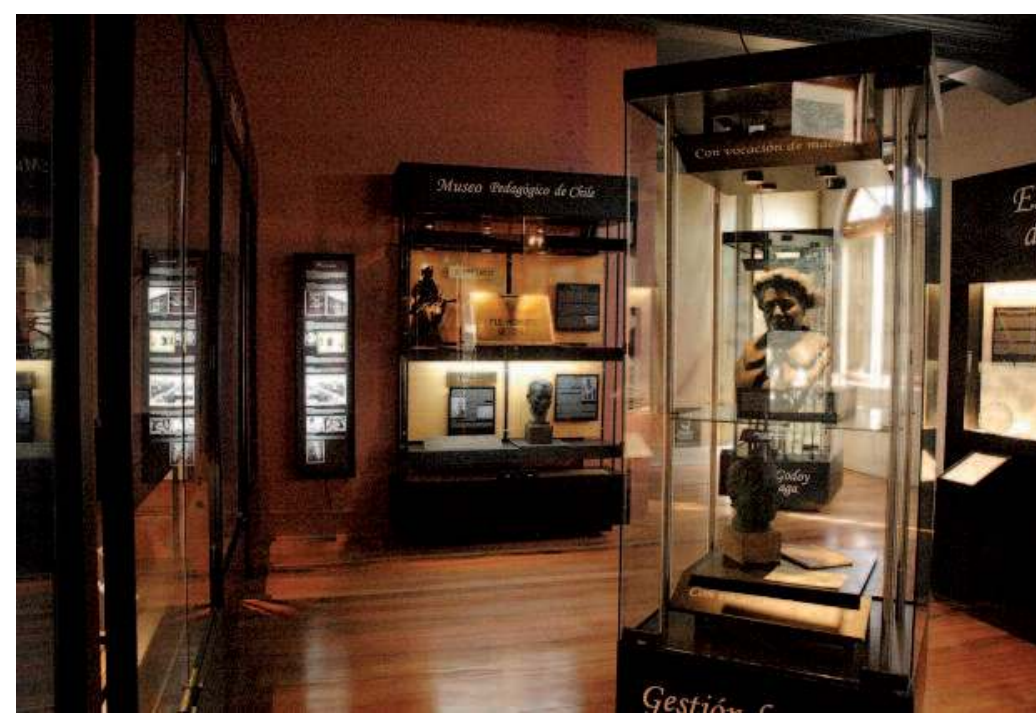

Vue générale d'une des salles d'exposition ๑) MEGM/Cristian Becker 
une conception d'un État actif dans le domaine culturel, donnèrent au projet de rénovation et de réouverture du musée une signification sociale et stratégique. C'est dans ce contexte que vit le jour, au sein de la direction nationale des Bibliothèques, Archives et Musées (DIBAM) du ministère de l'Éducation et plus précisément de la sous direction des Musées, l'idée de rénover l'ancien musée pédagogique (dorénavant musée de l'Éducation Gabriela Mistral) et de le remettre à la disposition de la collectivité. Le projet s'insère au demeurant dans le cadre d'une politique générale définie par cette sous direction visant à redynamiser et à repositionner les 23 musées qui fonctionnent sous sa tutelle.

Les axes de réflexions qui ont présidé à l'élaboration du projet

Le projet de rénovation et de réouverture du musée fait donc suite, d'une part, au processus de redéfinition des pratiques éducatives et culturelles de l'État chilien et, d'autre part, aux recherches effectuées sur la relation musée/école et les processus de médiation dans le contexte des musées scientifiques post dictature. Il repose sur trois axes de réflexion : le rapport entre institution et culture ; la notion de musée ; et la relation musée/école.

\section{Le rapport entre institution et culture}

Le bouleversement culturel de la société chilienne qui s'est opéré depuis une quinzaine d'années se traduit par la mise en place de démarches de participation et de collaboration entre différents acteurs. Pour que cet accès à la culture et à la démocratisation de la connaissance puisse s'opérer, non seulement au niveau du discours mais bien plus, au sein d'un espace public ouvert à tous, il est indispensable de fonder un socle de nouvelles valeurs socialement partagées. Ainsi, le premier axe de réflexion concernant le processus de rénovation du MEGM se fonde sur l'idée que les institutions muséales ne peuvent être uniquement l'expression de la culture officielle ignorant les intérêts véritables, le vécu et les attentes de leurs publics potentiels.

Dans ce cadre de réflexion, les notions d'institution et de culture ne peuvent être des concepts isolés. Turmel (1997) met l'accent sur le rapport entre ces deux termes (6). Tout au long de son fonctionnement, l'institution est productrice de culture et de pratiques sociales, celles-ci modèlent des modes de socialisation et de représentations de savoirs : "L'institution constitue un ensemble de dispositions et d'aménagement qui sont culturellement et socialement construits autour d'une activité sociale et qui tendent à se perpétuer dans l'espace et le temps » (Turmel, 1997). La culture - qui ne fait pas uniquement partie des représentations sociales du réel et des constructions sociales - doit avoir une structure qui véhicule le système de valeurs et d'actions engendrées à partir d'une société donnée. Voilà l'importance des institutions, elles deviennent finalement le " récipient »dans lequel la culture prend son sens et se légitime vis-à-vis d'un ensemble d'acteurs sociaux. Les institutions se constituent alors comme l'interface naturelle pour rendre possible la diffusion du savoir. Ce savoir, sous la forme d'un apprentissage particulier, trouve du sens dans des institutions capables de contenir et partager les connaissances acquises $(7)$.

Dans ce contexte, le mot «culture » ressort donc avec toute la force qu'implique le rapport entre des individus qui n'appartiennent pas nécessairement à la même culture d'origine. Il s'agit d'une ouverture sur le monde bien particulière car elle est conditionnée et traversée par les représentations des agents intervenants. Dans le cadre de cette diversité culturelle, nous avons voulu comprendre comment les différents acteurs en jeux se positionnaient par rapport au processus de rénovation et de réouverture du musée. Ainsi, nous avons cherché à connaître leurs attentes, leurs a priori, leurs préjugés, leurs besoins par rapport au musée et, plus particulièrement, par rapport à la nouvelle trame narrative. Le plus souvent, le fait de ne pas considérer ces différents acteurs concernés devient un obstacle majeur à l'heure de concevoir les expositions et cela empêche l'établissement d'une relation plus avantageuse entre l'institution muséale

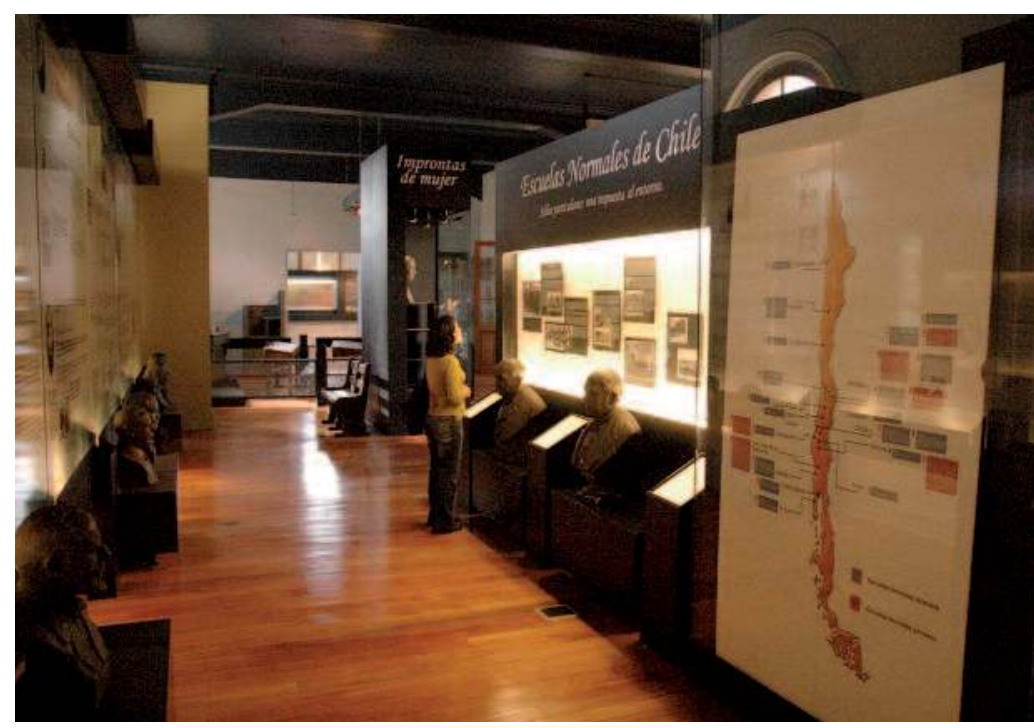

Les grands défis de la formation des maîtres : les écoles normales chiliennes (c) MEGM/Cristian Becker 
et ses publics potentiels. La nécessité de connaître et d'identifier les différentes visions se révèle comme un défi pour tous ceux qui s'intéressent à la relation de la structure muséale avec son entourage.

Ainsi, par l'intermédiaire d'un processus de muséologie participative et moyennant plusieurs rencontres avec les différents acteurs sociaux, divers points de vue sur l'éducation et la manière dont celle-ci devait être montrée et diffusée, ont été pris en compte. À partir de ces réflexions et autocritiques, le musée doit s'adapter et devenir une interface naturelle entre des acteurs sociaux représentatifs de la variété et de la pluralité de cette mosaïque de spécificités qu'est la culture. En d'autres termes, il acquiert une importance fondamentale en tant qu'opérateur culturel, capable de concentrer et de contenir des pratiques culturelles diverses et souvent juxtaposées.

\section{La notion de musée}

Le second axe de réflexion concernant le projet de rénovation renvoie à l'idée que le musée n'est pas seulement l'expression du passé d'un pays, «un bâtiment poussiéreux et coupé du monde ", "dépositaire d'antiquités » qui en vertu de leur usage ou de leur mérite ont gagné le droit d'être rassemblées là, souvenirs et témoins de ce qu'un jour nous fûmes. Lorsque les premiers musées sont apparus en Europe, ils se voulaient une sorte d'écran où se reflèterait un monde auquel le citoyen ordinaire n'avait normalement pas accès (Girault, 2003). Cette conception, fondée sur la notion d'un « musée d'objets », cherchait à mettre le monde à la portée visuelle du spectateur. C'était sans compter sur le

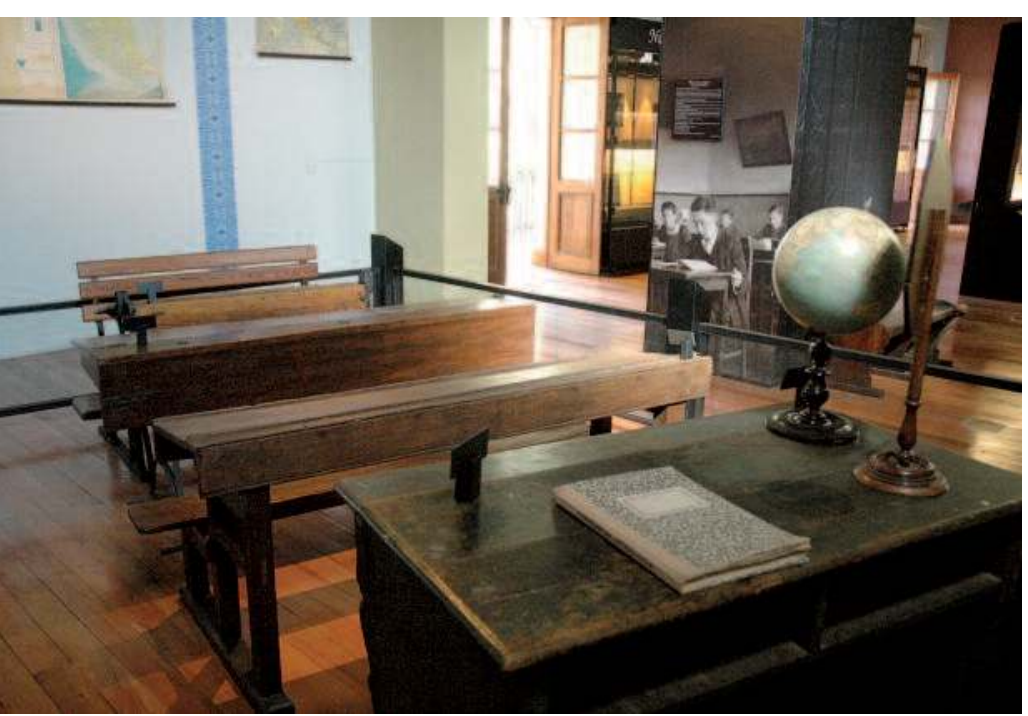

Les principes et les outils de l'art d'enseigner : la salle de classe (c) MEGM/Cristian Becker progrès vertigineux des sciences et le développement des technologies des communications et de la société de la connaissance, qui font que, malgré l'existence de grands fossés économiques, sociaux et culturels, l'individu contemporain peut accéder principalement grâce aux médias - à la connaissance de lieux et de cultures éloignés. Ainsi, les distances géographiques s'amenuisent, du moins du point de vue médiatique, et le musée perd son hégémonie en tant que lieu de concentration et d'approche des cultures du monde ; il devient donc un espace de diffusion et de remaniement des idées, espace dans lequel l'objet, de nature polysémique, ne peut plus avoir une valeur seulement intrinsèque, mais est au contraire fonction du contexte dans lequel il est immergé (Orellana, 2005).

Même s'il n'existe pas un consensus autour du concept de culture et des effets qu'il porte sur les institutions de transmission du savoir, il nous semble que le musée est bien un lieu de culture, dans le sens où il est un lieu d'échanges. Cette conception n'implique pas l'idée que le musée soit l'endroit où l'on développe simplement une culture, assez restreinte ; au contraire l'institution muséale doit dépasser les frontières nationales en prenant en compte les cultures locales. Or, si l'on accepte que le musée est un lieu de culture, il faut accepter aussi qu'il recrée des modèles conceptuels qui font partie d'une société déterminée. Sur la base de ces modèles, l'équipe du MEGM a élaboré l'exposition et créé les outils muséologiques et pédagogiques pour rapprocher la trame narrative des publics potentiels. Dans cette nouvelle approche, le musée s'est hissé au rang d'espace public (Habermas, 1992), un espace public de médiation où le visiteur peut former sa propre opinion sur un sujet déterminé et «négocier» sa relation au savoir (Rasse, 1997). C'est ainsi que se fait jour une nouvelle fonction du musée, maintenant vitrine des cultures locales et «musée d'idées », en se transformant en une institution porteuse de sens et d'identité, dans laquelle le spectateur se reconnaît et à travers laquelle il a la possibilité d'accéder aux connaissances et de projeter sa culture audelà des frontières locales.

De cette façon, on peut penser que les musées participent de moins en moins à l'expression de la culture « officielle », pour se constituer de plus en plus comme une interface entre les différents secteurs sociaux, représentant de fait la variété et la pluralité de cette mosaïque de spécificités qu’on appelle « la culture ». Dans cette optique, les musées modernes doivent s'orienter vers une recherche réflexive des 
finalités qui les définissent et vers l'affirmation des différentes cultures qui composent les sociétés où ils encadrent leur action : «le paradoxe de l'identité permet de toucher du doigt un mouvement complexe, tout à la fois d'homogénéisation interne des civilisations et de définition des unes par rapport aux autres. On va ainsi pouvoir rechercher les variations subtiles de la culture, et observer les mouvements sociaux de différenciation et de repli, ou d'adhésion et d'ouverture aux autres " (Rasse, 1997).

De ce fait, le MEGM en tant qu'institution sociale porteuse de sens et d'identité peut faire figure d'excellence étant donné la multiplicité de représentations sociales, de langages et de savoir-faire qu'il a été appelé à mobiliser dans le cadre de la définition de sa trame narrative et de la mise en place de son exposition permanente. Cependant, ce constat rend compte de la complexité à mener une politique de publics cohérente quels que soient les acteurs intervenants et nous permet de visualiser l'ampleur des

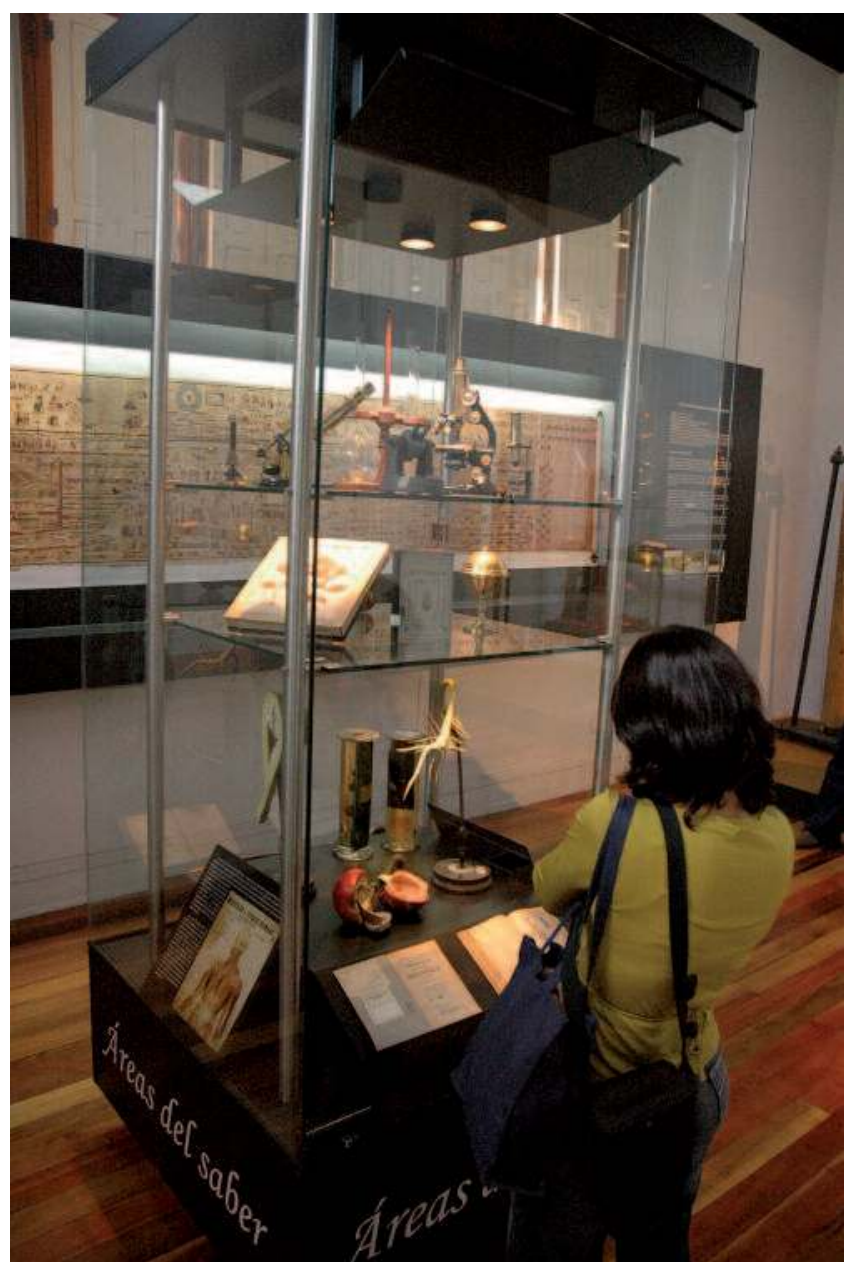

Les principes et les outils de l'art d'enseigner : l'enseignement des sciences contradictions qui sous-tendent le rapport entre le musée et ses partenaires potentiels.

\section{La relation musée/école}

Le troisième axe de réflexion qui a présidé à la rénovation du MEGM est lié au rapport de l'institution muséale avec le milieu scolaire. Ainsi, en considérant les résultats de notre recherche doctorale (Orellana, 2005) et en reprenant les travaux d'auteurs tels que Cohen (2001), Girault (2003) et Fortin-Débart (2004), nous avons voulu éviter une scolarisation excessive de l'espace muséal, dérive issue d'une représentation utilitaire de l'institution. À cet égards, nous nous sommes rendu compte que cette institution ne pouvait pas justifier son existence par le fait qu'elle pallie les carences d'une école incapable de générer ses propres méthodes d'apprentissage et dépourvue des moyens financiers pour dispenser une éducation de qualité. Le MEGM devait donc s'ouvrir sur la société dans son ensemble y compris l'école. C'est pour cette raison que nous avons intégré dans la trame narrative les réflexions et les thématiques répertoriées au cours du processus de muséologie participative.

\section{Quelques résultats du processus de muséologie participative}

De la réflexion décrite plus haut se dégage donc la nouvelle conception muséologique du MEGM qui, basée sur le concept de "musée d'idées ", a voulu faire de cette institution un référent des processus socio-éducatifs mis en œuvre dans le pays depuis le début de la République (Orellana, 2006). Pour atteindre cet objectif, et par l'intermédiaire d'une expertise pluridisciplinaire qui a donné lieu à un processus axé sur la relation entre les visiteurs potentiels et l'institution, l'équipe du musée a bâti son argumentaire.

Il s'agissait d'une part, de relier l'ancien musée pédagogique à sa communauté d'origine à travers une participation effective des futurs visiteurs et, d'autre part, de permettre une gestion plus démocratique de la culture. Nous étions convaincus que le seul moyen d'ouvrir l'accès au musée à tous les secteurs de la société était de faire participer les différents types de publics : des professionnels des musées publics et privés; des responsables de musées publics et privés ; des historiens; des enseignants en exercice; des enseignants à la retraite ; des enseignants normaliens ; des enseignants en formation initiale, des lycéens, et des organisations sociales et des habitants du quartier d'implantation du musée. "Chacun étant recruté dans le but d'apporter des connaissances issues de son propre champ d'action dans les domaines de l'éducation et de la 
pédagogie. À partir de là, des associations de quartiers, représentant l'ensemble des habitants vivant près $d u$ musée y sont associées, et ceci dans le but ultime de définir, à travers un système relativement complexe de muséologie participative, une stratégie d'approche et d'intégration de la communauté, basée sur la réciprocité des réflexions menées. Il est donc question, ici, d'une assemblée pluridisciplinaire, comprenant divers niveaux d'expertise, allant de celle du professionnel, ou celle $d u$ scientifique, à celle de l'amateur et du visiteur lambda » (Seron, 2006).

Dix rencontres ont ainsi été organisées au musée entre 2000 et 2005. Ces rencontres, qui duraient entre deux et quatre heures, s'articulaient autour de quelques questions ouvertes posées par un médiateur. Les thèmes traités étaient très variés : les témoins révélateurs de l'éducation chilienne ; le rôle de l'institution muséale vis-à-vis de la communauté ; la relation école/musée ; les manières d'enseigner (la pédagogie, concept et théorie, les méthodes et les outils de l'enseignement, les théories éducatives, les stratégies pour la médiation...) ; les collections (la présentation et la conservation des collections, l'importance des objets et de leurs contextes, la distribution spatiale des objets et les circuits de leur itinéraire)... Tout cela dans le but d'intégrer les contenus et les propositions culturelles de nos visiteurs potentiels et de révéler les inquiétudes et les demandes des acteurs concernés. Par l'intermédiaire de cette méthode participative, nous avons mis en perspective "des thèmes révélateurs pour l'ensemble ou pour une partie déterminée

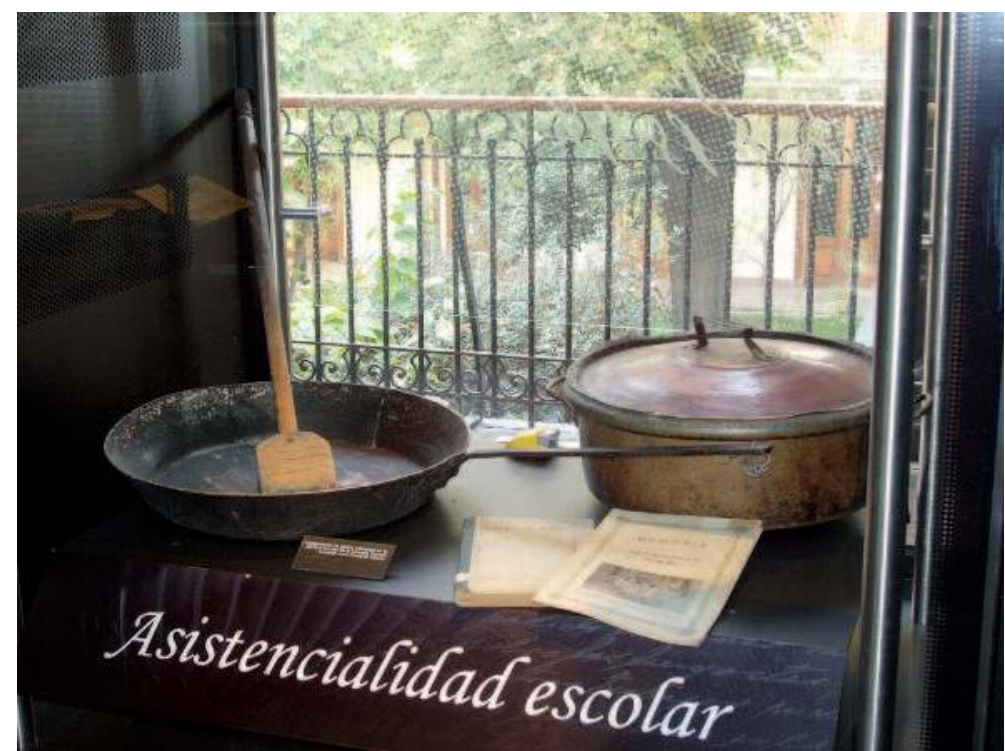

Les agents éducatifs et la construction de la citoyenneté : les mouvements associatifs d'assistance, la société des Colonies scolaires ๑) MEGM/Cristóbal Sepúlveda de la communauté, introduisant dans l'espace muséal des sujets de réflexion que celle-ci considérait comme pertinents (suivant le principe de l'évaluation préalable) » (Seron, 2006). Cela nous a permis de présenter des contenus en fonction des propositions faites lors des réunions de travail. C'est dans la diversité des approches répertoriées au cours de ce processus, que nous avons conçu la trame narrative de l'exposition. Ainsi, sur la base de l'information récoltée, consolidée et analysée, cette trame s'est articulée autour de quatre atmosphères muséographiques :

- La reconstruction de la mémoire individuelle et collective, - Les grands défis de la formation des maîtres,

- Les principes et les outils de l'art d'enseigner,

- Les agents éducatifs et la construction de la citoyenneté.

L'exposition permanente du MEGM est organisée autour de deux concepts - patrimoine et mémoire qui traversent toutes les salles et forment le fil conducteur permettant de mettre en exergue les grands processus collectifs qui ont donné naissance à l'Histoire de l'éducation chilienne. Le choix de ces deux concepts vise, d'une part, à susciter chez les visiteurs un goût pour la conservation et la gestion rationnelle du patrimoine tangible et intangible et, d'autre part, à contribuer à la reconstruction du passé en tant que fondement historique de la consolidation du système démocratique actuel et futur ${ }^{(8)}$. Dans cette ligne argumentaire, de nouvelles lignes historiographiques ont été considérées comme par exemple l'Histoire des mentalités. À partir des résultats du processus de muséologie participative, le début de l'exposition (première salle) met ainsi également l'accent sur les histoires croisées du bâtiment et du musée, comme révélateurs des contradictions qui ont traversé l'Histoire de l'éducation.

La visite se poursuit dans une deuxième salle consacrée aux grands défis collectifs qui ont marqué le mouvement de professionnalisation de l'enseignement et notamment à l'Histoire des écoles normales qui virent le jour sous l'impulsion des idées en cours au début de la République au milieu du XIX siècle et dont l'importance a perduré jusqu'au début des années 1970: les mouvements corporatistes et le caractère décentralisé des écoles normales. Les autres institutions, comme l'institut pédagogique et les universités, ayant joué un rôle clé dans la formation et le perfectionnement des maîtres ne sont pas oubliées. Les différentes politiques éducatives sont également présentées : la promulgation de la loi sur l'instruction primaire obligatoire de 1920 et l'action des gouvernements de Front populaire qui entre 1935 et 1945 donnèrent une nouvelle impulsion à l'éducation. 
La troisième séquence est consacrée aux principes et aux outils mis en œuvre dans les salles de classe depuis la deuxième moitié du XIX ${ }^{\mathrm{e}}$ siècle. Apparaissent ainsi les outils et les ressources didactiques en tant que médiation dans l'acquisition du savoir et l'enseignant comme facilitateur de moyens pour atteindre ces objectifs. Les disciplines de la connaissance sont à l'honneur : langage, Sciences naturelles (Zoologie, Botanique et Biologie), Mathématiques, Sciences de la Terre et de la Mer, Physique, Chimie, Calligraphie... Il est également fait référence à l'organisation du temps et de l'espace à l'école, avec l'introduction de la cloche et de la pendule dans la salle de classe ainsi qu'aux méthodes de discipline du corps et du caractère avec les châtiments corporels et moraux. La dernière salle d'exposition permanente est dédiée aux agents éducatifs et à la construction de la citoyenneté. L'un des principaux agents éducatifs dans l'Histoire de l'éducation au Chili a été l'État qui inculque par le biais de l'éducation formelle le concept de nation et le sens de la citoyenneté, en incorporant dans la vie quotidienne à l'école les symboles patriotiques. Cet espace prend en compte les organisations qui ont surgi de la société civile comme

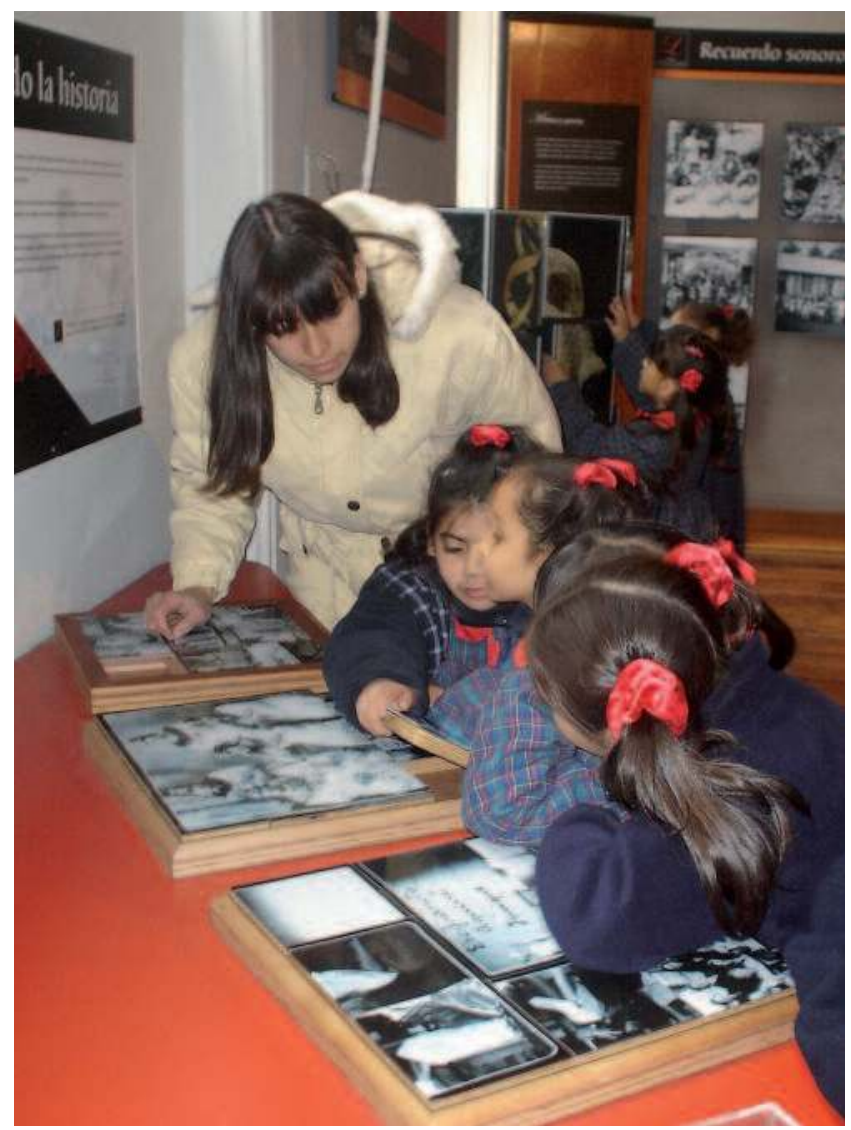

Une classe maternelle travaille dans la salle récréative. (๐) MEGM/Cristóbal Sepúlveda une réponse aux carences de l'État dans certains domaines, telles que la «société des Colonies scolaires » qui organisa et finança des sorties récréatives pour les élèves des écoles publiques et prit en charge des aspects liés à l'hygiène et à la santé des écoliers. Une salle récréative - un espace interactif, type salle de découvertes, dont le but est de conjuguer l'enseignement et l'apprentissage à partir d'une dimension cognitive, mais aussi émotionnelle - complète cet ensemble. Cet espace se veut une synthèse de la visite au musée, tout étant un espace de médiation (indépendant du reste du musée) qui peut être visité en dehors de l'exposition permanente. Le type d'action attendu dans cette salle interpelle les émotions et favorise le dialogue intergénérationnel : les concepts de médiation, signification, jeu et interactivité constituent le noyau autour duquel se développent les différentes activités proposées.

En définitive, le projet de rénovation du musée a cherché à reconstituer un pan de la mémoire nationale, moyennant la production d'une réflexion qui fait appel à la participation active de différents publics potentiels reliant les concepts exposés avec leurs représentations sociales, leurs attentes et leurs émotions. Les concepts, autour desquels s'articule l'exposition (patrimoine et mémoire), concourent à partir du rapport connaissance/visiteur, à la réaffirmation des multiples identités nationales et proposent une vision plus globale et holistique de la fonction de cette institution et son rapport avec ses différents publics. La communauté au sens large a donc trouvé une place dans le musée.

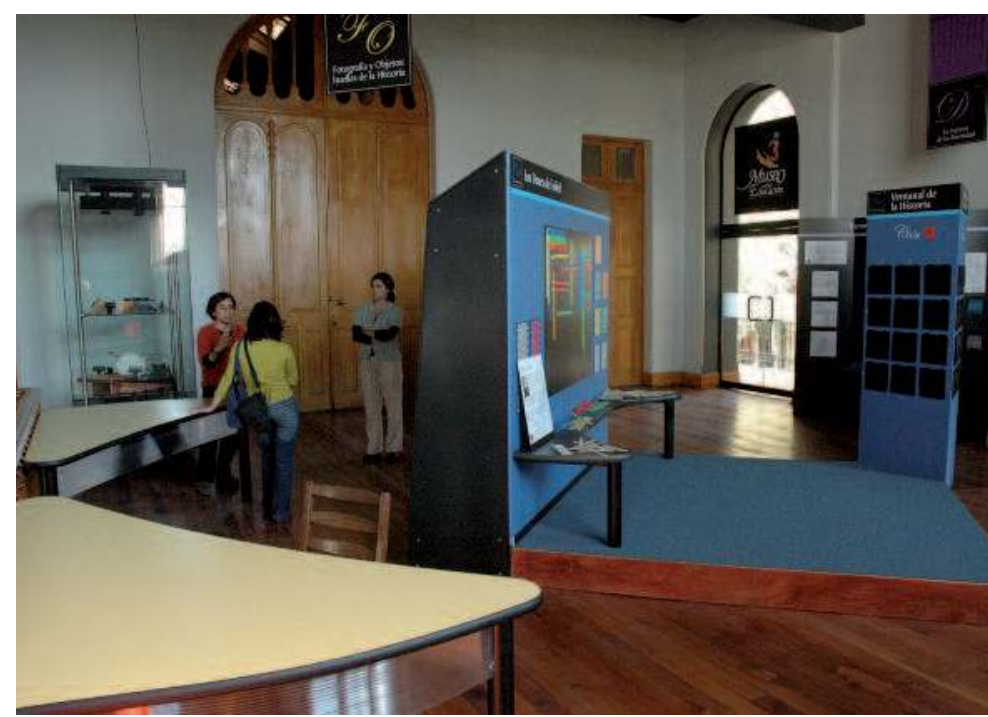

La salle récréative (c) MEGM/Cristian Becker 
Enfin, le processus de muséologie participative a ainsi permis de vérifier que l'orientation du projet donnée par l'équipe répondait à une demande réelle : intégrer les différents acteurs dans le processus de conception muséologique, connaître les thèmes que la communauté considérait comme les plus pertinents à être intégrés dans la trame narrative et prendre le recul nécessaire pour renforcer, rejeter ou réorienter les idées de l'équipe concernant la mise en place de l'exposition.

Cependant, même si la muséologie participative est au cœur d'un renouveau de la pratique muséale, il faut remarquer qu'elle présente aussi quelques limites : la représentation et l'expertise des acteurs interpellés, la diversification de l'offre culturelle, les déviations méthodologiques au moment de mettre en pratique cette forme de muséologie, l'élaboration du discours (parfois trop militant)... De plus, le fait de mettre en place un processus de participation au sein du musée " ne veut pas dire pour autant que cette participation active du visiteur entraîne un déplacement de la prise de décision »(Seron, 2006), car celle-ci demeure la prérogative de l'équipe et des responsables du musée et dépend aussi de leur expérience et de leurs intuitions. Nous sommes tout à fait conscients que l'utilisation de la muséologie participative n'assure ni le succès, ni la qualité de l'exposition, ni du produit final (dans notre cas, un musée ouvert et renouvelé). Il reste encore beaucoup à faire pour rapprocher l'espace muséal de la communauté. Cependant, nous pensons que l'utilisation de cette méthode contribue à faire réfléchir sur la finalité du musée et de ses collections et à renforcer les liens de celui-ci avec la société dans laquelle il est inséré ; tout cela dans le but de procurer à ses visiteurs un accès à la culture plus démocratique, participatif et concerné.

\section{Notes}

(1) Cette étape a été appelée par les médias « processus de redémocratisation », mais face à l'impossibilité méthodologique d'expliquer au lecteur la nature réelle de ce concept si ambigu, lorsqu'on fait appel à une transformation si hétérogène et si diverse, il nous a semblé plus pertinent d'emprunter le terme utilisé en sciences politiques « transition à la démocratie ». Par ailleurs, dès que nous parlons de transition à la démocratie, nous faisons appel à un processus qui a été vécu d'une façon très différente selon les pays. Pour en savoir plus sur ce processus, se référer à : Garretón, M.A. Revisando las transiciones democráticas en América Latina, in Estados y actores en un mundo complejo, revue Nueva Sociedad, $\mathrm{n}^{\circ} 148$, mars-avril 1997 ; O'Donnell, G. Contrapunto : ensayos escogidos sobre autoritarismo y democratización. Buenos-Aires : Editorial Paidos, 1997.
(2) Dans le cas du Chili, les changements sociaux et politiques intervenus depuis la fin de la dictature ont mis les acteurs sociaux dans l'obligation de redéfinir leurs pratiques culturelles (Garretón, 2003).

(3) C'est à l'issue de cet enjeu que, de nos jours, dans la plupart des pays latino-américains les gouvernements sont en train de mettre en place des réformes éducatives (citons l'exemple de l'Argentine, la Bolivie, le Guatemala, le Mexique, le Venezuela et le Chili). Pour en savoir plus, lire : Gajardo, M. Reformas educativas en América Latina. Balance de una década, in Gajardo et Puryear Formas y reformas de la educación en América Latina, Santiago du Chili : LOM Ediciones, 2003.

(4) Le MEGM est une institution axée sur l'Histoire de l'éducation dont la mission est orientée vers une contribution pertinente à la connaissance et au développement des multiples dimensions des processus socioéducatifs au Chili, moyennant la réunion, la conservation, l'enrichissement, la recherche et la diffusion du patrimoine pédagogique du pays.

(5) En ce qui concerne le bâtiment qui abrite le musée, il s'agit d'un immeuble inauguré en 1886 qui correspond à l'ancienne École normale de jeunes filles $n^{\circ} 1$ « Brígida Walker ». À l'époque de son ouverture, ce bâtiment a été considéré comme un modèle d'établissement scolaire autant pour la solidité de sa construction que pour son projet éducatif. Ainsi, le caractère nomade du musée dû à l'absence de bâtiment propre, rejoint ici un autre symbole marquant de l'Histoire de l'éducation chilienne : l'École normale $n^{\circ} 1$ qui jusqu'en 1973 fut l'un des sièges principaux de la formation du corps enseignant féminin. C'est là que Gabriela Mistral (Prix Nobel de littérature en 1945) passa ses examens de normalienne, raison pour laquelle le musée a pris son nom depuis sa réouverture le 8 mars 2006.

(6) Pour préciser le concept d'institution, André Turmel établit une distinction entre institution, établissement et organisation lorsqu'il s'agit de parler de la dichotomie entre culture et diffusion de savoir.

(7) Lorsque nous voulons mettre en exposition une trame narrative, il nous faut d'abord reconnaître que le musée a un bagage, un certain nombre d'éléments sous-jacents, une philosophie, une mission, en rapport avec un encadrement institutionnel et qui s'exprime aussi bien sous la forme de l'écrit que sous la forme de l'image.

(8) Le musée se veut interculturel et intergénérationnel ; ainsi, au fil des relations établies entre son patrimoine et les différentes catégories de visiteurs, s'élabore et/ou se reconstruit peu à peu la mémoire individuelle et collective.

\section{Bibliographie}

Cohen, C. Quand l'enfant devient visiteur : une nouvelle approche du partenariat École/Musée. Paris : Édition L'Harmattan, 2001.

Cruz, N. El surgimiento de la Educación Secundaria Pública en Chile. 1843-1876. (El Plan de Estudios Humanistas). Santiago du Chili : Éditions de la direction des bibliothèques, des archives et des musées, 2002.

De La Jara, I. et Garcia-Huidobro, N. Sala Re-creativa del Museo de la Educación Gabriela Mistral : ¿se puede mediar la historia ? in Actes du Primer seminario internacional sobre mediación cultural en ciencia y sociedad, Santiago du Chili : MEGM, 2006. 
Fortin-Débart, C. Le partenariat École-Musée pour une éducation à l'environnement. Paris : Éditions L'Harmattan, 2004.

Garreton, M.-A. (dir.) El espacio cultural latinoamericano. Bases para una política cultural de integración. Santiago du Chili : Fondo de Cultura Económica, 2003.

Girault, Y. (dir.) Le musée de science : d'un parti pris épistémologique à la prise en compte des publics in Girault (dir.) L'accueil des publics scolaires dans les Muséums, Aquariums, Jardins Botaniques, Parcs Zoologiques, Paris : Éditions L'Harmattan, Paris, 2003, pp. 15-50.

Habermas, J. L'espace public trente ans après, Quaderni, n ${ }^{\circ}$, 1992, pp. 161-191.

Orellana, M.-I. La relation école/musée au Chili : le nouveau rôle des musées scientifiques dans le contexte de la réforme éducative chilienne. Thèse de doctorat, Muséum national d'Histoire naturelle, Paris, 2005.
Orenalla, M.-I. Mediación, cultura y museos : el renacer del Museo de la Educación Gabriela Mistral, in Actes du Primer seminario internacional sobre mediación cultural en ciencia y sociedad, Santiago du Chili : MEGM, 2006.

Rasse, P. Techniques et cultures au musée. Lyon : Presses universitaires de Lyon, 1997.

Seron, E. La muséologie participative concepts et expérimentations. L'expérience d'un comité de visiteurs au nouveau musée de l'Homme. Mémoire de Master II Recherche, Culture \& Communication (section muséologie) université d'Avignon et des Pays du Vaucluse, 2006.

Turmel, A. 1997 Le retour du concept d'institution, in Culture, institution et savoir, Turmel, A. (dir.) Québec : Les presses universitaires de Laval, 1997, pp. 1-24. 